\title{
Resistencia a la autoridad y revolución en los siglos XVII y XVIII: Locke y Kant
}

Resistance to the authority and revolution in the seventeenth and eighteenth centuries: Locke and Kant

BRUNO VENDRAMIN

Abogado, Universidad Nacional de Córdoba. Diplomado en Derecho Constitucional, Universidad de Salamanca. Maestrando del Máster en Estudios Jurídicos Avanzados (Especialidad Derecho Público), Universidad de Barcelona. Correo electrónico: brunovendraminn@gmail.com

\section{Resumen}

A fines del siglo XVII, y durante el $X V I I I$, resurgió con fuerza la discusión acerca de la resistencia a la autoridad. Ello se dio a causa del clima político que se vivía en Inglaterra, las colonias norteamericanas y Francia, y por la renovación de la teoría política sucedida en la modernidad. En este escenario, Locke y Kant, testigos principales de los acontecimientos revolucionarios, escribieron in extenso sobre si es posible que el pueblo se subleve ante órdenes injustas. El primero justificó jurídica y filosóficamente la resistencia; por el contrario, Kant la rechazó de manera contundente. El presente artículo desarrolla, en primer lugar, el pensamiento de Locke sobre el derecho de resistencia, y lo sitúa en el contexto inglés de fines del siglo XVII $y$, en segundo lugar, la filosofía jurídica de Kant sobre el problema, y reconstruye la relación de ella con la Revolución Francesa. Por último, se explica el tratamiento que hicieron del derecho de resistencia los textos jurídicos franceses, en especial la Declaración de Derechos del Hombre

\section{Resumen}

The discussion about resistance to authority has strongly resurfaced at the end of the seventeenth century and in the course of eighteenth. This occurred as result of the political climate that existed in England, the North American colonies and France, and also because of the political theory renewal that took place during modernity. In this context, Locke and Kant, witnesses of the revolutionary events, wrote extensively on whether it is possible for the people to rise up against unjust orders. Locke philosophically justified the resistance; on the other hand, Kant rejected it forcefully. Firstly, this article develops the thought of Locke about this issue and places it in the English framework at the end of the XVII century and, second, describe the legal philosophy of Kant on this problem, and reconstructs the relation of it with the French Revolution. Finally, we explain the treatment of the French legal texts by the right of resistance, especially the Declaration of the Rights of Man and the Citizen of 1789 and the 
Perspectivas Revista de Ciencias Sociales - ISSN 2525-1112 | Año 4 No. 7 Enero-Junio 2019, pp. 245-262

y del Ciudadano de 1789, y la Constitución del año I de 1793.

Palabras clave

Resistencia a la autoridad Revolución - John Locke - Immanuel Kant
Citizen of 1789 and the Constitution of the year I of 1793 .

Keywords

Resistance to the authority Revolution - John Locke - Immanuel Kant

\section{Introducción}

En la novela Echeverría, de Martín Caparrós -en la cual narra con maestría y sutileza las peripecias biográficas del poeta argentino del siglo XIX Esteban Echeverría-, se lee que en una reunión con políticos, literatos e ilustres personajes de la alta sociedad de Buenos Aires, le hace decir al poeta:

Cuando los gobernantes violan los derechos del pueblo o del ciudadano y no rigen las leyes que deberían ampararlos el más sagrado de los deberes es la insurrección, decía, ya casi a los gritos, para acabar con el tirano que se ha puesto en guerra contra su propia sociedad y restablecer el imperio de las leyes. (Caparrós, 2016:155).

Estas líneas condensan las principales ideas del derecho de resistencia, y es una buena descripción de cómo se entendió, en líneas generales -ya que filósofos y juristas han ofrecido los más variados argumentos-, en la filosofía política moderna, y en las revoluciones políticas del siglo XVII y XVIII. De hecho, Echeverría vivió cinco años en París, estudió a los iluministas, y se contagió del espíritu de las jornadas de julio de 1789. En plena época de la construcción del Estado argentino -concretamente en 1837-, Echeverría afirma, sin dudar, que un pueblo libre no puede soportar a los tiranos, so pena de vivir en un estado de servidumbre'.

Pero vayamos aún más atrás: en la tragedia homónima de Sófocles, Creonte, rey y tirano de Tebas, emite la ley ordenando que Polinice -invasor de Argos y consecuentemente calificado de traidor- no podrá recibir una sepultura digna y deberá ser enterrado a las afueras de la ciudad. Por entonces, los rituales fúnebres tenían una dimensión social y espiritual fundamental, ya que sin ellos se creía que el alma vagaría errante por la tierra eternamente. Como es conocido, Antígona desobedece a Creonte y le da a su fallecido hermano la sepultura ritual. Condenada a muerte por el tirano, se ahorca. Desde el drama existencial de Antígona, el derecho

\footnotetext{
${ }^{1}$ En particular, Echeverría y compañía debatían sobre la legitimidad y conveniencia o no de otorgar al caudillo Juan Manuel de Rosas, por entonces Gobernador de Buenos Aires, la suma del poder público y facultades extraordinarias. En una palabra: todo el poder. Que, finalmente, se lo entregaron.
} 
de resistencia ha sido una constante ininterrumpida en la cultura y en el pensamiento occidental. La pregunta que subyace desde hace siglos permanece: ¿está justificado desobedecer órdenes jurídicas que son esencialmente injustas?

Con el nacimiento de la filosofía política en Grecia, la resistencia ha ocupado a todos -o a casi todos- los autores que han pensado la política: Platón, al reflexionar acerca de la democracia y su degeneración, la tiranía, y qué podía o debía hacer el pueblo frente al tirano; atraviesa la Edad Media, puesto que los filósofos cristianos se plantearon los límites a la obediencia del poder terrenal con Tomás de Aquino, Juan de Salisbury, que justificó el tiranicidio en su Policraticus, Marsilio de Padua y Guillermo de Ockham. Luego continúa con Francisco Suárez, Francisco de Vitoria y la Escuela Jurídico-Teológica de Salamanca, el célebre tratado anónimo (aunque firmado por un desconocido "Stephanus Junius Brutus") Vindicae contra tyrannos. Posteriormente, la reflexión adquiere un estatuto central en la Modernidad, con nombres como Althusius, Locke, Kant, Jefferson, Thoreau, hasta autores contemporáneos como Bobbio, Arendt, Habermas, Rawls y Ferrajoli, entre otros. Además, dicho derecho ha sido receptado por varias constituciones contemporáneas e integra la realidad jurídico-política de algunos países. Por ejemplo, en Europa está en la Constitución de Alemania, Grecia y Portugal; en Latinoamérica en las de Paraguay, Cuba, Venezuela, Honduras, Argentina y Ecuador.

El presente escrito se circunscribirá al tratamiento del derecho de resistencia en la filosofía política moderna y, más concretamente, en el pensamiento de John Locke (1632-1704) e Immanuel Kant (1724-1804), que, escribieron sendas líneas sobre el tema, pero fundamentalmente porque los dos son claros exponentes de la justificación filosófica (Locke), como de su rechazo (Kant). Como primera cuestión, cabe señalar que ambos filósofos trabajaron con métodos distintos: así en el caso de Locke, al asumir una postura marcadamente empirista, sus reflexiones encuentran eco en las inducciones que realiza de la realidad política de su tiempo; por su parte, Kant construye un edificio intelectual abstracto, en principio, su validez o invalidez no depende de la correspondencia con la realidad, aunque perseguirá conjugar el pensamiento filosófico con la práctica política.

Si es verdad, como ha escrito John Figgis, que "no existe característica más general del siglo XVII que la noción de la no-resistencia a la autoridad" (Figgis, 1942:172), por las monarquías que gobernaban por obra y gracia del derecho divino, es verdad también que en el siglo XVIII asistimos a un resurgimiento de la discusión de la resistencia a la autoridad, renacimiento que se dio a causa del clima político que se vivía en Inglaterra, Francia y en las colonias inglesas norteamericanas, y por las nuevas teorías políticas de la época. Ahora bien, como ha señalado Rubio Llorente, es importante destacar que la justificación de la resistencia se hizo vía derecho natural (Rubio Llorente, 1975:919).

Al mismo tiempo, esta reconstrucción histórico-conceptual permitirá ingresar en el tratamiento que hicieron de la resistencia las Declaraciones de Derechos, producto de las revoluciones liberales, tales como la francesa y la norteamericana; el Bill of Rights inglés nada dice acerca de la resistencia a la opresión. 
La estructura del escrito es la siguiente: primero veremos el pensamiento de Locke acerca del derecho de resistencia, y allí mismo analizaremos su relación con la Revolución de 1688, ya que el filósofo inglés simpatizó con los principios de dicho acontecimiento, y colaboró activamente para que Guillermo de Orange acceda al poder. La noción de revolución en el pensamiento de Locke cobra un sentido singular, puesto que la entiende como la resistencia activa y persistente de la ciudadanía frente a los gobernantes que han perdido la legitimidad popular.

Posteriormente, estudiaremos la resistencia en la filosofía jurídica de Kant. Íntimamente vinculada con ella, en la Revolución Francesa la resistencia a la opresión recibió expresa positivización en los documentos jurídicos, especialmente en la Declaración de Derechos del Hombre y del Ciudadano de 1789 -influida por la Declaración de Independencia americana y las Declaraciones de Derechos de los Estados particulares de la Unión-, y también en la Constitución jacobina del año I de 1793, por lo que es preciso detenerse en el análisis de ambos textos. En este sentido, Kant concibió a la Revolución Francesa como un traspaso de poder antes que como un acontecimiento que alteró de manera radical el orden social y creó un orden nuevo. Por último, concluiremos brevemente sobre lo escrito para hacer un balance de las ideas expuestas.

\section{Locke y la Revolución Gloriosa de 1688}

Locke fue un ferviente admirador de la Revolución inglesa. En efecto, participó activamente para que Guillermo de Orange acceda al poder. Cuando Jacobo II -último monarca católico- es coronado Rey en 1687, algunas facciones y grupos protestantes reaccionaron fuertemente, ya que no querían nuevamente otro Rey católico. En esos años, Locke se encontraba en Holanda. Allí entró en contacto con Guillermo de Orange y sus acólitos, y desde Rotterdam colaboró con ellos para derrocar a Jacobo. En el momento en que Guillermo desembarca en Inglaterra con sus ejércitos y María -hija de Jacobo, pero protestante-, las fuerzas de Jacobo II pasan al bando invasor y, el por entonces Rey, emigra a Francia, consumándose la Revolución e iniciándose la Monarquía Parlamentaria, o Constitucional, que perdura -con algunos matices- hasta la actualidad con el sistema de Westminster.

Con Guillermo III en el Gobierno, Locke regresa a Inglaterra en 1689. Establecido definitivamente en Londres y muy cercano al nuevo régimen (de hecho, en 1696 fue nombrado consejero del Board of Trade, cartera del gobierno británico que dirigía el comercio interior), publica, el Segundo Tratado sobre el Gobierno Civil, en 1690. Un aspecto fundamental que es preciso remarcar en este contexto es que el libro está dedicado al "Gran Restaurador", es decir Guillermo, que por "amor a sus justos y naturales derechos, junto con su resolución de preservarlos, salvaron a la Nación cuando esta se hallaba al borde la esclavitud y la ruina."2 (Locke, 2010:3-4). La obra se encuentra inseparablemente ligada a los acontecimientos de 1688. De hecho, en

\footnotetext{
${ }^{2}$ El libro apareció en edición anónima, más no por razones políticas, sino por la personalidad de Locke, que prefirió la discreción y el perfil bajo.
} 
muchas partes del libro Locke refiere dichos sucesos. Históricamente, el nombre Locke y la Revolución Gloriosa han ido de la mano³.

Por otra parte, pese a que el Bill of Rights nada dice expresamente acerca del derecho de resistencia, o la facultad de insurrección del pueblo inglés frente al Rey Jacobo II, es evidente que en el sentido de sus declaraciones subyace la justificación de la revolución (y utiliza evidentemente argumentos similares a los que, como veremos, desarrolla Locke), en cuanto denuncia el abuso de poder y las violaciones a las libertades colectivas e individuales que perpetró el por entonces destronado Jacobo II al eludir al Parlamento al momento de tomar decisiones. Así pues, dice el texto que el Rey "se esforzó en subvertir y proscribir la religión protestante, y las leyes y libertades de este Reino", y la forma en que lo hizo fue "usurpando y ejerciendo el poder de dispensar de las leyes y aplazar su entrada en vigor y su cumplimiento, sin el consentimiento del Parlamento."

Al mismo tiempo, los atropellos y los abusos fueron varios: encarceló a prelados y obispos que se negaron a consentir su régimen; creó un Tribunal especificó para las causas eclesiásticas; estableció tributos de forma distinta de los instituidos por el Parlamento; violó la libertad de elegir a los miembros del cuerpo legislativo; e impuso multas excesivas. Estos son algunos de los ejemplos de toda una serie de actos abusivos, los cuales son "total y directamente contrario a las leyes, ordenanzas y libertades de este Reino." Por tal razón, es claro que, en el Bill of Rights, la justificación de la deposición de Jacobo II y la coronación de Guillermo de Orange vienen dadas por el incumplimiento de los deberes más básicos del gobernante.

\section{El derecho de resistencia en Locke ${ }^{4}$}

\footnotetext{
${ }^{3}$ Peter Laslett (1915-2001), profesor de Cambridge, especialista en Locke y teoría política inglesa, ofreció poderosos argumentos contra la convencional y extendida tesis que afirma que el Segundo tratado es una justificación filosófico-política de la Revolución. Para Laslett "no pudieron ser los acontecimientos de 1688 los que hicieron que Locke fijara su atención en la naturaleza fundamental de la sociedad y de la política, en la personalidad ciudadana y la propiedad, en los sagrados derechos del individuo y en los imperativos éticos a que debiera someterse la función de gobernar. La combinación de asuntos que hizo que su mente reflexionara sobre todos estos problemas debe buscarse en un período anterior. De hecho, los Dos Tratados no son la racionalización de una revolución necesitada de defensa, sino la llamada a una revolución que aún no había realizado." (Locke, 2010: XIX-LXXV). Laslett observa que fue en 1679-1681 cuando Locke pensó las ideas que luego volcó en el Segundo Tratado. Entre otras razones, Laslett enuncia las lecturas y el círculo de Locke. Defendió la causa de los whigs en la llamada Crisis de la Exclusión de 1679-1681; desde 1681 se vincula de cerca de Shaftesbury -por entonces se encontraba preso en la Torre de Londres por participar en actividades a favor del Parlamento-; en ese mismo año leyó minuciosamente las obras de Knox -Historical Relation of Ceylan- y la Ecclesiastical Polity de Hooker, que lo marcó profundamente; por las cartas que escribía desde Holanda, en las cuales surge que por esa época ya estaba ideando la escritura del Segundo tratado. Y una razón fundamental: Locke pretendió refutar la teoría de la monarquía divina de Robert Filmer, que escribió en su célebre Patriarcha (1680). Principalmente lo hizo en el Primer tratado, pero también en el Segundo tratado se aboca a ello, sobre todo en relación con la fundamentación del liberalismo y la no sujeción a ningún patriarca original.

${ }^{4}$ Las reflexiones acerca del derecho de resistencia en el Segundo tratado las encontramos en los dos últimos capítulos, el dieciocho "De la tiranía", y el diecinueve "De la disolución del Gobierno".
} 
Perspectivas Revista de Ciencias Sociales - ISSN 2525-1112 | Año 4 No. 7 Enero-Junio 2019, pp. 245-262

Locke, por esos años, tiene ante sí un problema filosófico-político concreto. En palabras de Rawls, el problema era

formular el derecho de resistencia a la Corona al amparo de una constitución mixta (...) El argumento de Locke es que Carlos II, al haber abusado de la prerrogativa y de otros poderes, se había comportado como un monarca absoluto y, con ello, había disuelto el régimen. (Rawls, 2009:165).

Su teorización acerca de si el pueblo puede resistir ante el monarca está estrechamente vinculada con la situación política de la que es testigo. Pero el pensamiento de la resistencia no se agota en la coyuntura en la que vive el filósofo británico, sino que es una consecuencia directa de su teoría general acerca del origen del gobierno, su legitimación y sus fines, que, a su vez, está íntimamente relacionada con su concepción del individuo y de la sociedad.

Bajo este orden de ideas, la sociedad civil se constituye a través de un contrato ${ }^{5}$. Locke es uno de los máximos representantes del contractualismo del siglo XVIII. El origen del gobierno y su legitimación residen exclusivamente en el consentimiento voluntario de los ciudadanos -esta tesis es sumamente importante para justificar la resistencia a la autoridad-. Previo a la instauración de la sociedad política, los hombres vivían en estado de naturaleza. En este estado, todos nacen libres e iguales y tienen ciertos derechos, que Locke califica de "inalienables", a saber: la libertad, la vida y la propiedad.

La sociedad política se constituye para que los derechos puedan ser garantizados plenamente y para evitar el estado de guerra, instituyendo una autoridad que ponga fin a las disputas. En este sentido, los límites del gobierno son estos derechos; el poder público no puede violarlos ni alterarlos ${ }^{6}$, porque estaría incumpliendo el fin principal para el que fue establecido: "el grande y principal fin que lleva a los hombres a unirse en Estados (Commonwealths) y a ponerse bajo un gobierno es la preservación de su propiedad." (Locke, 2010: 124). Locke entiende genéricamente por "propiedad" los tres derechos: la vida, las libertades y las posesiones. Víctor Méndez Baiges sostiene que son los binomios "derechos-contrato" y "estado de naturaleza-sociedad civil" la clave para entender la "justificación, legitimidad, alcance y sentido" de la filosofía política de Locke. (Locke, 2010:235-274).

Ahora bien, establecido el estado civil e instituido el gobierno, surge una pregunta fundamental: ¿cuándo está justificada la resistencia al gobierno? ¿Qué condiciones

\footnotetext{
5 "Lo que crea una comunidad y saca a los hombres del desorganizado estado de naturaleza llevándolos a formar una sociedad política es el acuerdo que cada individuo hace con los demás, con el fin de incorporarse todos y actuar como un solo cuerpo, constituyendo de este modo un Estado claramente definido." (Locke, 2010:204).

${ }^{6}$ Este punto es un pilar fundamental de la filosofía política de Locke y del liberalismo que luego recogen las Declaraciones de Derechos del siglo XVIII: los derechos individuales como límite infranqueable ante el potencial abuso del poder del Estado.
} 
políticas, legales y sociales tienen que darse para que el pueblo pueda levantarse y utilizar la fuerza contra el gobierno?

En primer lugar, advierte que la insurrección no es tan fácil que cunda en la sociedad y se expanda. En algunos países la persona del rey o príncipe es sagrada -está pensando en el caso francés que, a la sazón, gobernaba Luis XIV- por lo que está exento de toda responsabilidad, no podrá nunca utilizarse la fuerza contra él y por tanto el gobierno se mantendrá incólume. En segundo lugar, en el caso de las órdenes que emite el rey y que ejecutan los subalternos, Locke alega que si estos se exceden en su autoridad es totalmente nulo, porque "lo que da derecho a actuar no es el haber recibido un mandato, sino la autoridad de quien lo manda, no habiendo autoridad alguna cuando ésta va contra las leyes." (Locke, 2010:200). En este caso, tampoco está en peligro la autoridad del rey. En tercer lugar, cuando hay remedios legales y judiciales a disposición para revertir alguna injusticia, los ciudadanos deben acudir a ellos buscando la reparación e indemnización. Aquí tampoco hay razón para rebelarse. Por último, si se cometen injusticias en casos aislados y particulares de individuos, éstos si se resisten "perderán con toda seguridad", ya que es imposible que unos pocos individuales quiebren la estructura del gobierno.

Pues bien, para que el pueblo resista a la autoridad debe darse, según Locke, "una larga cadena de acciones": una acción gubernamental repetitiva, sistemática, pública y continuada en el tiempo. Asimismo, debe afectar a la mayoría del pueblo, "todo el mundo" dice Locke, ya que "si el pueblo ve que el poder arbitrario se manifiesta en varios casos", en este caso "¿cómo podría hombre alguno evitar buscar algún modo de salvarse?" (Locke, 2010:203).

En esta línea, el argumento central que ofrece Locke consiste en afirmar que, cuando el gobierno incumple los fines para el cual se lo ha instituido y viola las "propiedades" del súbdito7, el pueblo puede legítimamente resistir a tales atropellos. Cuando el gobierno traiciona su misión,

estará devolviendo al pueblo el poder que éste le dio, y el pueblo tendrá entonces el derecho de retomar su libertad original y el de establecer un nuevo cuerpo legislativo que le parezca apropiado y que le proporcione protección y seguridad. (Locke, 2010:212).

Si el gobernante viola el contrato social, éste deja de tener vigencia alguna, los derechos individuales desaparecen, y cada individuo tiene la facultad de defenderse y resistir al agresor de sus propiedades.

El objetivo filosófico-político de Locke es establecer mecanismos institucionales sólidos para la protección de los derechos individuales. De ahí proviene la justificación

\footnotetext{
7 "El poder legislativo actúa en contra de esa misión que se le ha encomendado cuando trata de invadir la propiedad del súbdito y de hacerse a sí mismo, o a cualquier otro grupo de la comunidad, amo y señor de las vidas, libertades y fortunas del pueblo." (Locke, 2010:211).
} 
Perspectivas Revista de Ciencias Sociales - ISSN 2525-1112 | Año 4 No. 7 Enero-Junio 2019, pp. 245-262

de la resistencia, y por esta razón a lo largo del Segundo tratado es tan categórico en la formulación de los argumentos. Por ejemplo, cuando afirma

que quien, ya sea gobernante o súbdito, intenta invadir por fuerza los derechos del pueblo, y da así fundamento para que se eche abajo la constitución y el régimen de cualquier gobierno justo, es culpable del mayor crimen de que un hombre es capaz (...) Y quien hace eso puede justamente ser considerado como enemigo y peste de toda la humanidad, y debe ser tratado como se merece. (Locke, 2010:221).

Por otra parte, a Locke no le importa si el que abusa del poder es uno, encarnado en la figura de un monarca absoluto $0,-y$ he aquí una tesis problemática que Kant discutirá, y asumirá una postura contraria a Locke- si es un parlamento instituido por la voluntad popular, y elegido conforme a derecho. Locke quiere dejar bien claro que no le importa la forma de gobierno; todas las formas pueden terminar volviéndose tiránicas y corromperse ${ }^{8}$, porque

siempre que el poder se ha depositado en cualesquiera manos para el gobierno del pueblo y para la preservación de sus propiedades es utilizado con otros fines y se emplea para empobrecer o someter a los súbditos a los mandatos abusivos de quien los ostenta, se convierte en tiranía. (Locke, 2010:195).

Entonces si el gobierno -bajo cualquier forma jurídico-institucional que adopteincumple con los mandatos para los que fue establecido, para Locke estamos ante una tiranía. El razonamiento de Locke es simple pero contundente: "Allí donde termina la ley empieza la tiranía." (Locke, 2010:196).

Otro argumento importante que ofrece Locke es la operación de inversión que efectúa con el abuso del poder del gobierno. Es decir: que el pueblo tenga la facultad de procurar un nuevo gobierno, destituyendo al que viola sus derechos y traiciona su confianza es, precisamente, "la mejor defensa contra la rebelión, y el medio más probable de evitarla." Como los hombres han instituido la sociedad política para excluir el estado de guerra, y para sancionar leyes que garanticen sus derechos, "quienes de nuevo usen la fuerza para echar abajo esas leyes serán los que están rebelándose, del latín rebellare, es decir, los que estén trayendo de nuevo el estado de guerra; y éstos serán los rebeldes, propiamente hablando." (Locke, 2010:217). El rey o parlamento que no cumpla con las leyes, que no respetan los fines para los que fueron establecidos y violan las propiedades de los ciudadanos, a estos ha de

\footnotetext{
${ }^{8}$ El gobierno en su conjunto, en todas sus ramas y órganos, tiene la obligación de cumplir las leyes y ninguno puede excederse en el poder, visto que "exceder los límites de la autoridad que uno tiene es algo a lo que no tiene derecho ni el gran ministro ni el pequeño funcionario." (Locke, 2010:197).
} 
acusarles de rebeldes y merecen su reprobación, pero no el pueblo que se defiende, de manera legitima, de estas violaciones.

Luego de justificar la resistencia, Locke se centra en una pregunta importante: ¿Quién juzga si el rey o el parlamento están actuando contra los intereses del pueblo? ¿El pueblo? ¿La misma autoridad? ¿Un tercero externo? La respuesta es indudable: el que debe juzgar es el conjunto del pueblo: pues, si el pueblo otorgó un mandato, un encargo, una tarea, y ésta no se cumple, ¿quién mejor que el que ha "encomendado la misión y conserva el poder de destituirlo cuando el depositario del encargo no lo cumple?" (Locke, 2010:232). Ahora bien, ¿qué ocurre si el príncipe o el parlamento rechazan este arbitraje del pueblo? ¿Si hay un conflicto entre lo que cree y siente el pueblo y el gobernante rechaza este sentimiento?

En este punto, Locke echa mano de su célebre metáfora que utiliza a lo largo del Segundo tratado: la "apelación al cielo". Si el soberano y el pueblo están en desacuerdo sobre si existió extralimitación de poder en la actuación del gobierno, y visto que no hay juez superior en la tierra, entonces "la única apelación posible ha de ser dirigida a los cielos", pues "cada hombre juzgará por sí mismo, en éste y en todos los demás casos, si otro hombre se ha puesto en estado de guerra con él, y si debe apelar al Juez Supremo, como hizo Jefté." (Locke, 2010: 233).

\section{El derecho de resistencia en Kant}

Kant fue uno de los filósofos centrales de la modernidad. Podría afirmarse que reflexionó sobre todo -o casi todo- el campo del conocimiento humano: ética, derecho, religión, metafísica, estética, física, matemática. Entre sus disquisiciones acerca del derecho y la moral, el filósofo de Konigsberg pensó hondamente la noción de resistencia a la autoridad. Los análisis kantianos acerca de este derecho se encuentran en el breve ensayo publicado en 1793, bajo el título "En torno al tópico: Tal vez eso sea correcto en teoría, pero no sirve para la práctica", que contiene tres artículos ${ }^{9}$, el que nos interesa aquí es el que lleva por título "De la relación entre teoría y práctica en el Derecho Político (Contra Hobbes)". También teorizó sobre la insubordinación en la Doctrina del Derecho, primera parte de La metafísica de las costumbres, de 1797. Vamos a prestar especial atención al primer escrito porque allí Kant expone, de forma clara y precisa, cada uno de los argumentos por los cuales rechaza la resistencia a la autoridad.

Estamos en 1793: la Revolución Francesa ya ha sucedido, siendo el acontecimiento capital de la época, que captó la atención de filósofos y pensadores. De hecho, Kant fue un ferviente admirador de las jornadas de julio de 1789 (como veremos más adelante, aquí muchos autores hablan de una paradoja, pues ¿cómo se explica la simpatía a la Revolución y su rechazo sobre el derecho de resistencia?). Al mismo tiempo, el filósofo de Konigsberg ha publicado sus tres Críticas -la primera, la Crítica

\footnotetext{
${ }^{9}$ Los artículos son "Acerca de la relación entre teoría y práctica en la Moral (En respuesta a unas cuantas objeciones del profesor Garve)", "De la relación entre teoría y práctica en el Derecho Político (Contra Hobbes)", y "De la relación entre teoría y práctica en el Derecho internacional, considerada con propósitos filantrópicos universales, esto es, cosmopolitas (Contra Moses Mendelssohn)".
} 
de la razón pura, en 1781 y 1788; la Crítica de la razón práctica, en 1788; y la Crítica del juicio, en 1790-, en consecuencia, su proyecto filosófico se encuentra maduro y consolidado. Así pues, es en este contexto que se pregunta acerca de si es legítimo o no resistir a la autoridad.

Adelantando el resultado de los argumentos, Kant fue un tenaz opositor del derecho de resistencia. Antes de ingresar a analizar sus ideas, es forzoso hacer una aclaración: su oposición es una consecuencia lógica de su sistema filosófico, y de las leyes morales y jurídicas que lo sustentan. Es decir: para comprender su rechazo a que el pueblo se subleve ante órdenes legales injustas o ante un tirano, es preciso analizarlo en el marco general de sus principios acerca del Estado, la Moral y el Derecho, ya que, como se mostrará, se encuentran íntimamente imbricados.

En primer lugar, el filósofo de Konigsberg comienza explicando qué es un estado civil: en este estado las personas firman un contrato con el objetivo de establecer una comunidad política y, consecuentemente, dar lugar a un Estado sometido al Derecho, es decir instaurar una constitución civil. El fin de esta tarea "viene a ser el derecho de los hombres bajo leyes coactivas públicas, mediante las cuales se puede atribuir a cada uno lo que es suyo y garantizárselo frente a una usurpación por parte de cualquier otro." (Kant, 1993:26). Asimismo, dicho estado se funda en los siguientes principios: 1- la libertad de cada uno de los miembros de la sociedad, en cuanto hombre; 2- la igualdad de cada uno, en cuanto súbdito; y 3- la independencia, tomado al hombre en cuanto ciudadano. Instituido el orden jurídico bajo estos principios, el fin de estos es obligar "a todo legislador a que dicte sus leyes como estas pudieran haber emanado de la voluntad unida de todo un pueblo (...) Pues ahí se halla la piedra de toque de la legitimidad de toda ley pública." (Kant, 1993:37). Ahora bien, lo dicho es aplicable y vinculante para el legislador, mas no para el pueblo. ¿Qué sucede si el pueblo juzga que con determinada ley no está conforme y "perderá su felicidad"? ¿Qué puede hacer?

Antes de responder este interrogante es necesario aclarar que los principios de constitución del status iuridicus son a priori, esto es, independientes de la experiencia. Conforme su metafísica (que se interesa por cuáles son las leyes del conocimiento del mundo objetivo) y la moral (referido a las leyes puras de la ciencia de la ética), el interés que persigue Kant es fundar principios jurídicos fijos, donde su validez no dependa en manera alguna de la experiencia.

Dicho esto, la respuesta kantiana sobre si el pueblo puede rebelarse es inequívoca y contundente: "no le queda más remedio que obedecer" porque "todo levantamiento que estalle en rebelión, es el delito supremo y más punible de una comunidad." (Kant, 1993:40). Kant ofrece varias razones. En primer lugar, porque la felicidad de cada ciudadano individual, o de la sociedad en su conjunto, es esencialmente subjetiva, cambiante y contingente. La felicidad no puede sostenerse en ningún principio universal válido, son las subjetividades y las circunstancias las que definen la felicidad. La felicidad pública no puede quedar, en manera alguna, al arbitrio de lo que cada súbdito considere felicidad en determinado momento histórico. En este orden de ideas, Norbert Bilbeny escribe que "un derecho a la felicidad, además de ser subjetivo -la relatividad de la idea de felicidad no permitiría calificar tal derecho como objetivo- 
Perspectivas Revista de Ciencias Sociales - ISSN 2525-1112 | Año 4 No. 7 Enero-Junio 2019, pp. 245-262

nos hace pensar que puede dar origen a un uso inmoral del mismo." (Bilbeny, 1989:26). Así pues, cada cual puede buscar su felicidad como mejor le plazca, siempre y cuando no interfiera y perjudique la libertad general de la comunidad y, con ello, los derechos de los conciudadanos.

Por otra parte, la insurrección contra el orden jurídico es imposible porque destruiría los fundamentos mismos de la constitución estatal. Este argumento es central para Kant: el pueblo no está facultado a emitir juicios y oponerse constantemente sobre la actuación del jefe de Estado porque quebraría, cada vez que lo hiciera, los fundamentos de la comunidad jurídica. Si una ley pública es legítima desde el punto del derecho, con lo que trae aparejada la voluntad de coacción, sino no sería tal,

el poder que en el Estado da efectividad a la ley no admite resistencia (es irresistible), y no hay comunidad jurídicamente constituida sin tal poder, sin un poder que eche por tierra toda resistencia interior, pues ésta acontecería conforme a una máxima que, universalizada, destruiría toda constitución civil, aniquilando el único estado en que los Hombres puedan poseer derechos en general. (Kant, 1993: 40).

La prohibición a sublevarse es incondicionada porque ésta destruye el derecho, y con ello la libertad, la igualdad, y la independencia de los ciudadanos ${ }^{10}$.

El próximo paso que efectúa Kant es instalarse en la práctica política e histórica para ver qué sucede con el derecho de resistencia ${ }^{11}$. Con este fin observa lo ocurrido con la Revolución Gloriosa de 1688: el Bill of Rights de 1689, que nada dice acerca de la facultad del pueblo a resistir ante el Monarca ni ante el Parlamento, deja fuera de duda posibles rebeliones contra el poder instituido al establecer un sistema político basado en el Derecho.

Luego del ejemplo británico, Kant vuelve a la teoría y esboza otro argumento: afirma que sería una clara contradicción que una ley autorizara a rebelarse porque entonces la Constitución tendría que haber diseñado "un contrapoder públicamente constituido" y, en consecuencia, "sería preciso todavía un segundo jefe de estado que amparase los derechos del pueblo frente al primero" (Kant, 1993:45), cosa que es jurídica y prácticamente imposible.

Un punto de especial relevancia es que, si bien para Kant no se justifica -nunca, el deber de obedecer al jefe de Estado es incondicionado, absoluto y categórico- el derecho de resistencia, los ciudadanos tienen una facultad pública y colectiva valiosa:

\footnotetext{
${ }^{10}$ En La metafísica de las costumbres encontramos el mismo argumento: "La razón por la que el pueblo debe soportar, a pesar de todo, un abuso del poder supremo, incluso un abuso pensado como intolerable, es que su resistencia a la legislación suprema ha de concebirse como contraria a la ley, incluso como destructora de la constitución legal en su totalidad." (Kant, 2005:152).

${ }^{11}$ No hay que olvidar que el esfuerzo kantiano en este artículo es, precisamente, conjugar teoría y práctica. De allí el título "De la relación entre teoría y práctica en el Derecho Político (Contra Hobbes)". En sus palabras, "se trata del canon de la razón (en lo práctico), donde el valor de la práctica depende por completo de su conformidad con la teoría subyacente." (Kant, 1993:6).
} 
la libertad de pluma. Actualmente denominamos a este derecho como libertad de expresión o de opinión, y ha sido uno de los pilares de la filosofía ilustrada, como así también del liberalismo y de la democracia. Kant sostiene, contra Hobbes ${ }^{12}$, que el pueblo conserva sus derechos inalienables, aunque no puedan ser derechos de coacción. Hobbes, por el contrario, piensa que el soberano en ningún momento está vinculado con el pueblo mediante un contrato y por ello nunca puede incurrir en injusticia contra el ciudadano. En este sentido, si el soberano se equivoca con las leyes y perjudica a los ciudadanos, estos tienen la facultad de hacer público lo que les parece injusto. En efecto,

la libertad de pluma es el único paladín de los derechos del pueblo (...) Pues querer negarle esta libertad no solo es arrebatarle todo pretensión a tener derechos frente al supremo mandatario -como Hobbes pretende- sino también privar al mandatario supremo (...) de toda noticia sobre aquello que él mismo modificaría si lo supiera, dando lugar a que se ponga en contradicción consigo mismo. (Kant, 1993:46-47).

Analizado el trayecto teórico kantiano, es necesario situarlo en el tiempo histórico en que las reflexiones fueron escritas, y pensar su relación con la Revolución Francesa. Como dijimos al principio, el filósofo de Konigsberg fue un entusiasta admirador de dicho acontecimiento. ${ }^{13}$ ¿Cómo se explica la simpatía a la Revolución y su rechazo sobre el derecho de resistencia, derecho positivizado en el artículo 2 de la Declaración de los Derechos del Hombre y del Ciudadano de 1789, y también incluido en los artículos 33, 34 y 35 de la Constitución jacobina del Año I de 1793?

La clave para comprender esta aparente contradicción es el planteo kantiano de un objetivo de carácter eminentemente político: su oposición al derecho de resistencia viene dado para desautorizar a los enemigos de la Revolución a intentar recobrar el poder nuevamente y reinstalar el Antiguo Régimen. Bilbeny dice que

el lado político de su impugnación del derecho a la resistencia consiste en el desarme jurídico de los enemigos de la revolución, cualquiera que haya sido el fundamento de ésta, pero especialmente para aquella revolución originada por un cambio hacia la democracia. Para el caso de la Revolución Francesa, significa una

\footnotetext{
${ }^{12}$ De ahí que el opúsculo se titule "De la relación entre teoría y práctica en el Derecho Político (Contra Hobbes)".

13 Otros filósofos han interpretado a Kant como el pensador de la revolución francesa. Por ejemplo, Hannah Arendt señala que el abate Sieyés se hallaba ostensiblemente influenciado por el pensamiento político de Kant. En una carta de su amigo Anton Theremin le confiesa a Kant que Sieyés guardaba la intención de ingresar las reflexiones kantianas en Francia, "ya que el estudio de esta filosofía por parte de los franceses sería un complemento de la revolución." Por otro lado, Heine y Marx también observaron en Kant al principal filósofo de la Revolución Francesa. Esto ha sido señalado por Diego Tatián (2004:38).
} 
desautorización legal y moral de los partidarios de la vuelta de la monarquía legitimista. (Bilbeny, 1989:28).

Lo importante para Kant, en esta instancia, es que el nuevo régimen debe conservarse -como pensó Maquiavelo, lo importante para el Príncipe no es tanto conseguir el poder, sino conservarlo-. Como se funda en los derechos inalienables de los ciudadanos y en la soberanía popular, debe impedir que prospere cualquier intento de contrarrevolución o insurrección, so pena de destruir el nuevo orden jurídico. Pero, ¿qué implica la contrarrevolución? De nuevo, en palabras de Bilbeny: "La represión ejercida por los jacobinos y el Tribunal Revolucionario de París no puede ser condenada porque sus actos obedecen a la máxima de actuar en conformidad con lo que el pueblo soberano quiera para sí" (Bilbeny, 1989: 28). El poder político, que debe auto conservarse, tiene la obligación de impedir, por mandato de la soberanía popular, todo intento de contrarrevolución: para ello, cualquiera de los actos políticos ejecutados se encuentran justificados. Hay que recordar que, en 1793, el Terror de Robespierre se encontraba en plena época de dominio. En opinión de Kant:

Si una revolución ha triunfado y se establece una nueva constitución, la ilegitimidad del comienzo y de la realización no puede librar a los súbditos de la obligación de someterse como buenos ciudadanos al nuevo orden de cosas, y no pueden negarse a obedecer lealmente a la autoridad que ahora tiene el poder. (Kant, 2005:154-155).

Ahora bien, Kant discrepa con los revolucionarios en cuanto a la ejecución del rey Luis XVI, y rechaza firmemente el regicidio. En primer lugar porque si el rey destronado prefiere la "tranquilidad", y no recobrar el poder político, no puede ser demandado públicamente. Asimismo, el poder que detentó el monarca fue legal, en el sentido de que el pueblo no había ejercitado su derecho a la soberanía. Por otra parte, Luis XVI accedió a la petición del Parlamento de convocar elecciones a Estados Generales en 1788, y luego capitular en 1789, por lo que, para Kant, el rey entregó el poder libremente. El filósofo de Konigsberg cree que las jornadas de 1789 no fueron, en sentido estricto, una revolución, sino, antes bien, una transferencia del poder. Es decir: se desplegó un traspaso voluntario del poder "desde el monarca hasta su legítimo titular, el pueblo, sin que se diera el vacío de poder legal que transitoriamente se crea en toda revolución." (Bilbeny, 1989:29).

\section{El derecho de resistencia en el marco de la Revolución Francesa}

En términos jurídicos, la Declaración de los Derechos del Hombre y del Ciudadano constituyó el acontecimiento fundamental de la Revolución Francesa. La importancia de la Declaración, como ha dicho George Jellinek, es la de haber creado "la noción de los Derechos subjetivos públicos del individuo en el derecho positivo de los 
Perspectivas Revista de Ciencias Sociales - ISSN 2525-1112 | Año 4 No. 7 Enero-Junio 2019, pp. 245-262

Estados del continente europeo." (Jellinek, 2000:82). Así pues, implicó, entre otras cosas, la consagración y positivización concreta en el orden jurídico nacional, con base en el principio de la soberanía, de la teorización de los derechos naturales conforme se venía pensando desde el siglo XVI y XVII.

Es de destacar que una de las principales influencias de la Declaración francesa fue la Declaración de Independencia norteamericana del 4 de julio de 1776. La influencia del proceso revolucionario norteamericano sobre el francés ha sido harto demostrada por historiadores y teóricos políticos ${ }^{14}$. En este sentido, es ilustrativo lo que escribió Condorcet en su texto Influencia de la revolución en América sobre Europa (1786): "El espectáculo de un gran pueblo, donde los derechos del hombre son respetados, es útil para todos los demás, a pesar de las diferencias de clima, costumbres y constituciones." (Hunt, 2009:23). Por otra parte, en 1789 Jefferson estaba en París. A principios de ese año, el Marqués de La Fayette estaba escribiendo los borradores de la Declaración de Derechos para Francia, que lo hizo, como refiere Lynn Hunt en su ya clásico libro sobre los derechos humanos, "muy probablemente con la ayuda del propio Jefferson." (Hunt, 2009:15). Tanto el abate Sieyes como Lafayette comienzan a utilizar la expresión "derechos del hombre" (droits de l'homme), con clara influencia de la Declaración norteamericana, que hablaba con lenguaje lockeano de derechos inherentes e inalienables. Como dice Hunt,

la Declaración de Independencia de Estados Unidos insistía en que todos los hombres son creados iguales y en que todos ellos poseen derechos inalienables. De forma parecida, la Declaración de los Derechos del Hombre y del Ciudadano proclamó que los hombres nacen libres y permanecen libres e iguales en derechos. (Hunt, 2009:20).

Bajo este orden de ideas, la idea del derecho de resistencia recibió una sólida y refinada elaboración en el proceso revolucionario norteamericano. Con clara influencia de la filosofía política de Locke, para Thomas Jefferson, que fue uno de los principales actores de la independencia, y también redactor de los documentos jurídicos de la época, el derecho de resistencia ocupa un lugar primordial.

Jefferson definió una lista de graves agravios (los que figuran uno por uno en la Declaración) que había cometido el gobierno inglés a las colonias norteamericanas,

\footnotetext{
${ }^{14}$ Por el contrario, Jellinek sostiene que la fuente y el modelo legislativo de la Declaración francesa fueron los Bills of Rights de los Estados particulares de la entonces naciente Unión norteamericana, y no la Declaración de Independencia de 1776. El jurista alemán opinaba que fueron las primeras constituciones escritas de los Estados particulares de Norteamérica (por ejemplo, la de Virginia, la de Maryland, la de Massachusetts), que iban precedidas de declaraciones de derechos, teniendo el proyecto de Lafayette como pauta, además de que por la época circulaban diversas traducciones francesas de las Constituciones de los Estados de la Unión. No obstante, pese a esta divergencia de opiniones -la de Jellinek y la de Hunt-, la influencia del proceso revolucionario norteamericano sobre el francés es indudable.
} 
lo que, según él, produjo una sistemática violación a los derechos individuales y a la posibilidad de que se autogobiernen. En este sentido, en el pensamiento de Jefferson destaca el derecho de autogobierno, del que fue un tenaz defensor: el gobierno inglés impidió que las colonias se otorguen sus leyes y decidan sus propios asuntos. Así, "los británicos habían transformado al derecho en un instrumento de opresión, más que en un instrumento de libertad." (Gargarella, 2005:25). Para Jefferson, según Gargarella, la resistencia a la autoridad estaba justificada por dos razones: en primer lugar, por una "condición sustantiva", es decir, los severos abusos en sus derechos a los que el pueblo norteamericano fue sometido; en segundo lugar, por una "condición procedimental" (Gargarella, 2005:23-25), esto es, que las colonias no podían autogobernarse, estaban impedidas de darse sus leyes, de organizarse políticamente como mejor lo considerasen, y por no participar, tampoco, en la creación del derecho inglés que los regía en ese momento.

El derecho de resistencia recibió expresa positivización en los textos constitucionales y declarativos norteamericanos. Así, en la Declaración de Independencia del 04 de julio de 1776, que se adoptó de manera unánime por los trece Estados de la colonia, en su segundo párrafo refiere

que cuando quiera que una forma de gobierno se haga destructora de estos principios, el pueblo tiene el derecho a reformarla, o abolirla, e instituir un nuevo gobierno que se funde en dichos principios, y a organizar sus poderes en la forma que a su juicio ofrecerá las mayores probabilidades de alcanzar su seguridad y felicidad.

Naturalmente los gobiernos no deben abolirse tan fácilmente por motivos superfluos, o mínimos, o preferencias políticas de ciertos grupos opositores; para que se configure la opresión es preciso que ocurra "una larga serie de abusos y usurpaciones, dirigida invariablemente al mismo objetivo, evidencia el designio de someter al pueblo a un despotismo absoluto, es su derecho, es su deber, derrocar ese gobierno y proveer de nuevas salvaguardas para su futura seguridad y su felicidad", abusos y violaciones que sufrió el pueblo norteamericano por parte del Gobierno de Inglaterra.

Por otra parte, basta mirar las Declaraciones de Derechos y Constituciones de los Estados particulares de la Unión norteamericana para confirmar el peso y la presencia del derecho de resistencia en la revolución americana: así figura en la Constitución y Declaración de Derechos de Virginia de 1776; en la Constitución de New Hampshire de 1776; en la de Pennsylvania de 1776, que es conocida por su radicalidad; en la de Massachusetts de 1780.

Volviendo al contexto revolucionario francés, la Declaración de Derechos del Hombre y del Ciudadano, sancionada el 26 de agosto de 1789 por la Asamblea Nacional Constituyente, reguló expresamente el derecho de resistencia a la opresión, como así también hizo lo mismo la Constitución jacobina del año I de 1793. Es necesario aclarar que cuando se habla de la resistencia a la opresión -como ocurre con casi todas las 
cláusulas de los dos textos- se lo hace en términos de enunciados declarativos, esto es, generales, abstractos y asertivos, y no prescriptivos.

En este sentido, el artículo 2 de la Declaración de 1789 establece: "La finalidad de toda asociación política es la conservación de los derechos naturales e imprescriptibles del hombre. Tales derechos son la libertad, la propiedad, la seguridad y la resistencia a la opresión." La ubicación del derecho de resistencia en el artículo segundo es de capital importancia, y no está ubicado allí azarosamente: la intención del constituyente francés es declarar que el derecho de resistir a la opresión es un derecho natural, imprescriptible y subjetivo, que tiene por objetivo la tutela del individuo frente a la opresión de tiranos, monarca o cualquier persona que usurpe el poder y lo ejerza arbitrariamente, violando los derechos individuales, o anulando la separación de poderes (es necesario recordar que el art. 16 refiere que una sociedad donde no se encuentran garantizados los derechos ni hay separación de poderes, carece de Constitución).

De ahora en adelante, el único titular de la soberanía es el pueblo (art. 3), por tanto, tiene la facultad de resistir frente al ejercicio ilegítimo de cualquier gobernante que viole los derechos, ya que "ningún cuerpo, ningún individuo, pueden ejercer una autoridad que no emane expresamente de ella", esto es, de la soberanía popular. En el mismo sentido estableció el artículo 27 de la Constitución de 1793: "Que todo individuo que usurpe la soberanía sea al instante ejecutado por los hombres libres." Posteriormente, en la Constitución del año I de 1793 -aprobada el 24 de junio y luego derogada en 1795 por la Constitución del año III-, el derecho de resistencia también se encuentra regulado, pero con importantes diferencias respecto de la Declaración de 1789. En primer lugar, se inserta en el texto constitucional, en sus artículos 33, 34 y 35. En segundo lugar, se observa que el tratamiento es más extenso: si el artículo 2 de la Declaración se limitaba a declarar a la resistencia a la opresión como un derecho natural e imprescriptible, en la Constitución del año I habla de su relación con los otros derechos, define cuándo hay opresión y, por último, qué carácter tiene la resistencia cuando el gobernante viola los derechos de los ciudadanos. Además, en el primer texto sólo se nombra en un artículo, mientras que en el segundo en tres. Una de las razones de esta diferencia es que la primera es una Declaración de Derechos, y el segundo texto es una Constitución, donde el articulado es más largo ya que regula múltiples cuestiones de la vida de la nación.

Son los últimos tres artículos del texto constitucional de 1793 los que regulan in extenso el derecho de resistencia. El primero, el artículo 33, dispone que "la resistencia a la opresión es la consecuencia de los demás derechos del hombre". La idea que subyace en este artículo es que si la vida, la libertad, la seguridad y la propiedad no se encuentran garantizadas, y si los gobernantes violan estos sagrados y naturales derechos, los hombres cuentan, naturalmente, con la facultad de resistir al gobierno que abuse del poder y viole los derechos individuales, que posteriormente refiere el artículo 35. Es, como literalmente reza el texto, una consecuencia. Como expresaba el artículo 2 de la Declaración de 1789, la finalidad de toda asociación política es la conservación y el goce pleno de estos derechos, allí donde éstos no se 
cumplan a causa de la opresión, los hombres pueden resistir para que los mismos se tornen efectivos.

Continúa con el artículo 34, que está redactado de manera un tanto abstracta: "Hay opresión contra el cuerpo social cuando uno sólo de sus miembros es oprimido. Hay opresión contra cada miembro cuando el cuerpo social es oprimido." En la realidad política de la nación, si solo un ciudadano es oprimido difícil es que pueda configurarse un caso de insurrección contra un gobierno opresor, como demostró Locke en el Segundo ensayo; por otra parte, la segunda parte del artículo es más realista y sigue el pensamiento tradicional de la teoría de la resistencia, en cuanto determina que si el cuerpo social, esto es, la mayoría del pueblo es oprimido, entonces cada miembro es oprimido.

Por último, el artículo 35 del texto constitucional dispone que "cuando el gobierno viola los derechos del pueblo, la insurrección es, para el pueblo y para cada una de sus porciones, el más sagrado de los derechos y el más indispensable de los deberes". Este artículo recoge la teoría clásica del derecho de resistencia, con marcada influencia de la filosofía de Locke, si el gobierno viola los derechos individuales -que son, en última instancia, el objetivo que debe asegurar la Constitución- el pueblo puede resistir, y su acción está justificada. No obstante, el artículo va más allá, y con cierto tono romántico establece que es el "más indispensable de los deberes". Así, resistir a la opresión no sólo sería un derecho, sino también un deber, lo que abre una pregunta: si estamos ante un tirano que abusa del poder y viola de manera clara y notoria los derechos, si no cumple las leyes y no respeta la división de poderes, en fin, si no respeta la Constitución, los hombres que -ya sea deliberada o involuntariamente- no resisten, ¿pueden recibir algún tipo de sanción por haber colaborado o permitido la violación de los derechos del pueblo cuando cambie el gobierno, y no haber cumplido con este deber constitucional?

\section{Conclusiones}

A lo largo del artículo se analizó cómo Locke y Kant pensaron en profundidad la resistencia a la autoridad en sus respectivos contextos históricos, políticos, culturales y sociales. Al mismo tiempo, asumieron determinada posición frente a los cambios revolucionarios. En este sentido, los dos fueron simpatizantes de los mismos, de la Revolución Inglesa -el primero-de la Revolución Francesa -el segundo-.

Para Locke, la resistencia solo está justificada cuando el gobernante -no importa si es un rey o un parlamento, cualquiera puede ponerse en guerra contra el puebloincumple reiteradamente sus deberes y viola los derechos inalienables de los individuos. El derecho a resistir no es un derecho político ni legal, sino, antes bien, está fundamentado en el derecho natural, en los derechos individuales básicos, es decir, vida, libertad y posesiones, que el hombre ya tenía en el estado de naturaleza. Por su parte, Kant tenía como objetivo demostrar que el Estado de Derecho es absolutamente incompatible con el derecho de resistencia porque menoscaba sus presupuestos más básicos, siendo la oposición al régimen jurídico el mayor de los delitos. Al mismo tiempo, sus ideas sobre el tema son producto de su filosofía general, 
y de la necesidad de fijar principios fijos y a priori para el sistema jurídico. Por otra parte, y en relación a los acontecimientos de julio de 1789 , consideraba primordial asegurar la estabilidad del nuevo régimen frente al antiguo, por lo que rechaza rotundamente la posibilidad de insurrección.

Al mismo tiempo, se reconstruyó la vinculación de la resistencia a la autoridad con las revoluciones inglesa, norteamericana y francesa. Respecto de la primera, pese a que el Bill of Rights no regula este derecho, justifica el accionar revolucionario con razones contundentes: la violación de los derechos individuales y colectivos por parte de Jacobo II, el abuso de poder con el que gobernaba, y la cancelación de la actuación del Parlamento británico. Por otra parte, en la Revolución norteamericana recibió expresa positivización en sus textos, materializándose en la Declaración de Independencia del 04 de julio de 1776, en las Declaraciones de Derechos de los Estados particulares, como así también en sus Constituciones. En el ámbito de la Revolución Francesa -especialmente influida por el proceso norteamericano- se hizo letra en la Declaración de los Derechos del Hombre y del Ciudadano de 1789 y en la Constitución jacobina del año I de 1793.

Recibido: 21/01/2019

Aceptado: 08/06/2019

\section{Bibliografía}

BILBENY, N. (1989), "Kant y la revolución francesa. Refutación del derecho de resistencia civil”. Barcelona: Anuario de filosofía del derecho.

CAPARRÓS, M. (2016). Echeverría. Barcelona: Anagrama.

FIGGIS, J. N. (1942). El derecho divino de los reyes, México D.F.: Fondo de cultura económica.

GARGARELLA, R. (2005). El derecho a resistir el derecho. Madrid: Miño y Dávila.

HUNT, L. (2009). La invención de los derechos humanos. Barcelona: Tusquets.

JELLINEK, G. (2000). La declaración de los derechos del hombre y del ciudadano. México D.F.: Universidad Nacional Autónoma de México.

KANT, I. (2005). La metafísica de las costumbres. Madrid: Tecnos.

KANT, I. (1993). Teoría y práctica. Madrid: Tecnos.

LOCKE, J. (2010). Segundo tratado sobre el gobierno civil. Un ensayo acerca del verdadero origen, alcance y fin del gobierno civil. Madrid: Tecnos.

RAWLS, J. (2009). Lecciones sobre la historia de la filosofía política. Barcelona: Paidós.

TATIÁN, D. (2004), “Kant, la Revolución y la paz”. Córdoba: Universidad Nacional de Córdoba.

RUBIO LLORENTE, F. (1975). "La doctrina del derecho de resistencia frente al poder injusto y el concepto de Constitución”. Caracas: Libro homenaje a J. Sánchez Covisa. 